\title{
Structural and Electrical Characteristics of Solution-processed Copper Oxide Films for Application in Thin-film Transistors
}

\author{
Heonju Lee, ${ }^{1}$ Xue Zhang, ${ }^{1}$ Eui-Jik Kim, ${ }^{2}$ and Jaehoon Park ${ }^{1,2 *}$ \\ ${ }^{1}$ Department of Electronic Engineering, Hallym University, \\ 1 Hallymdaehak-gil, Chuncheon 24252, Korea \\ ${ }^{2}$ School of Software, Hallym University, \\ 1 Hallymdaehak-gil, Chuncheon 24252, Korea
}

(Received October 15, 2018; accepted December 3, 2018)

Keywords: sol-gel process, oxide semiconductor, copper oxide, thermal annealing, thin-film transistor

In this study, we investigated the effect of the annealing time of copper oxide $(\mathrm{CuO})$ on the morphological and chemical characteristics of films and the electrical properties of bottomgate/top-contact $\mathrm{CuO}$ thin-film transistors (TFTs). Thermogravimetric analysis showed that thermal annealing at $600{ }^{\circ} \mathrm{C}$ for $30 \mathrm{~min}$ and $3 \mathrm{~h}$ resulted in the formation of $\mathrm{CuO}$ films. The $\mathrm{CuO}$ films were analyzed by X-ray diffraction, X-ray photoemission spectroscopy, absorbance determination, and Raman spectroscopy. As the annealing time of the $\mathrm{CuO}$ film was increased, the composition of the films changed from $\mathrm{Cu}(\mathrm{OH})_{2}$ to $\mathrm{CuO}$. Considering the overall TFT performance, the optimal annealing time in solution-processed $\mathrm{CuO}$ semiconductors was determined to be $3 \mathrm{~h}$. These results suggest that the annealing time is crucial in modulating the chemical characteristics of solution-processed $\mathrm{CuO}$ thin films and the TFT performance.

\section{Introduction}

Over the past few decades, oxide semiconductors have received considerable attention because of their superior electrical conductivity, high optical transparency in the visible range, and excellent electrical conductivity. ${ }^{(1,2)}$ These essential characteristics of oxide semiconductors are highly advantageous for use in electronics and optoelectronics. In particular, oxidesemiconductor-based thin-film transistors (TFTs) are very promising in a wide range of electronic applications, such as electronic memory devices, sensors, and active-matrix displays. ${ }^{(3-5)}$ Most oxide TFTs are based on n-type semiconductors (e.g., $\mathrm{ZnO}, \mathrm{In}_{2} \mathrm{O}_{3}, \mathrm{ZnInO}, \mathrm{ZnSnO}$, and InGaZnO), but few p-type oxide TFTs have been reported owing to the lack of p-type oxide semiconductors and rigorous fabrication conditions. This is because of the nonideal electronic configuration of p-type oxide semiconductors: the valence band maximum is mainly composed of anisotropic and localized oxygen $2 p$ orbitals, resulting in a large hole effective mass and low mobility. Although high-performance p-type oxide semiconductors are difficult to realize, they are necessary for constructing complementary logic-based circuits, $\mathrm{p}-\mathrm{n}$ junction devices,

*Corresponding author: e-mail: jaypark@hallym.ac.kr https://doi.org/10.18494/SAM.2019.2160 
and oxide-based solar cells. ${ }^{(6)}$ Among p-type semiconducting oxides, copper oxide $(\mathrm{CuO})$ is a promising material owing to its nontoxicity, low cost, and abundance.

Solution processing is a simple, low-cost method for the fabrication of oxide semiconductors. However, this method has one important drawback: the thin-film properties are affected by the annealing temperature. For example, in the case of $\mathrm{CuO}$ films, it has been reported that $\mathrm{Cu}_{2} \mathrm{O}$ is converted to $\mathrm{CuO}$ during annealing at $250{ }^{\circ} \mathrm{C} .{ }^{(7)}$ Therefore, it is very important to study the influence of annealing conditions on the properties of $\mathrm{CuO}$ films to improve the performance of $\mathrm{CuO}$-based TFTs. In this study, we fabricated $\mathrm{CuO}$ thin films using a sol-gel solution process under ambient air conditions with copper(II) acetate hydrate as a precursor. The prepared sol and films were analyzed by thermogravimetry, X-ray photoemission spectroscopy (XPS), X-ray diffraction (XRD), and field-emission scanning electron microscopy (FE-SEM). The performance of the TFTs, in which a copper oxide layer was used as the semiconductor, was investigated by analyzing their output and transfer characteristics. In addition, we use in situ Raman spectroscopy to probe the characteristic changes of $\mathrm{CuO}$ films.

\section{Materials and Methods}

The $\mathrm{CuO}$ thin films were prepared by the sol-gel spin coating method. The precursor was prepared by dissolving $0.3 \mathrm{M}$ copper(II) acetate hydrate $\left[\mathrm{Cu}\left(\mathrm{CO}_{2} \mathrm{CH}_{3}\right)_{2} \mathrm{H}_{2} \mathrm{O}\right]$ in $5 \mathrm{ml}$ of 2-methoxyethanol $\left(\mathrm{CH}_{3} \mathrm{OCH}_{2} \mathrm{CHOH}\right)$ with $0.6 \mathrm{M}$ monoethanolamine. To obtain a homogeneously mixed precursor solution, the prepared solution was stirred with a rotation speed of approximately $750 \mathrm{rpm}$ on a hotplate at $75{ }^{\circ} \mathrm{C}$ for $1 \mathrm{~h}$ using a magnetic bar. For the fabrication of CuO-based TFTs with a bottom-gate/top-contact structure, a p-doped silicon substrate with a 100 -nm-thick silicon dioxide $\left(\mathrm{SiO}_{2}\right)$ dielectric layer was cleaned via sequential ultrasonication in acetone, isopropyl alcohol, and deionized water. The substrate was subsequently treated with an oxygen plasma for 2 min while an RF power of $45 \mathrm{~W}$ was applied and the oxygen flow rate was maintained at $9 \mathrm{sccm}$. This oxygen plasma treatment was indispensable for generating a hydrophilic surface suitable for the interface between the $\mathrm{SiO}_{2}$ dielectric and $\mathrm{CuO}$ semiconductor layers. The precursor solution was filtered using a 0.2 $\mu \mathrm{m}$ polytetrafluoroethylene syringe filter and then spin-coated on the oxygen-plasma-treated substrate at $2000 \mathrm{rpm}$ for $1 \mathrm{~min}$. In order to form the $\mathrm{CuO}$ semiconductor layer, the spincoated film was prebaked on a hotplate at $150{ }^{\circ} \mathrm{C}$ for $20 \mathrm{~min}$ and then annealed in a furnace at $600{ }^{\circ} \mathrm{C}$ for $30 \mathrm{~min}$ or $3 \mathrm{~h}$. Finally, 100 -nm-thick Au source and drain electrodes were thermally deposited on the semiconductor layer through a shadow mask. The channel width and length of the fabricated TFTs were 800 and $50 \mu \mathrm{m}$, respectively.

The chemical characteristics of the CuO films were investigated by XPS (K-Alpha, Thermo Scientific, Waltham, MA, USA), and the crystallographic properties were characterized by XRD (DMAX-2500, Rigaku, Tokyo, Japan). The surface morphologies of the films were examined by FE-SEM (S-4300, Hitachi, Ibaraki, Japan). The electrical characteristics of the TFTs were evaluated using a semiconductor analyzer (4200-SCS, Keithley, Seoul, Korea). Raman spectroscopy (LabRAM HR Evolution, Horiba Scientific, Kyoto, Japan) was performed to analyze the crystal structure of the films. 


\section{Results and Discussion}

Thermogravimetric analysis (TGA) (N-1000, Sinco, Korea) was used to analyze the thermal decomposition processes of the $\mathrm{CuO}$ precursor solution. The measurement was carried out by raising the temperature from 25 to $600{ }^{\circ} \mathrm{C}$ at a heating rate of $10{ }^{\circ} \mathrm{C} / \mathrm{min}$ in a nitrogen atmosphere. Figure 1 shows the TGA curve of the precursor solution in this experiment. We can see that the initial large weight loss $(>90 \%)$ of the precursor solution occurs below $100{ }^{\circ} \mathrm{C}$, this being a result of the evaporation of the solvent and the decomposition of the precursor. In this process, the $\mathrm{Cu}\left(\mathrm{CO}_{2} \mathrm{CH}_{3}\right)_{2} \mathrm{H}_{2} \mathrm{O}$ solution is hydrolyzed to $\mathrm{Cu}(\mathrm{OH})_{2}$. As the temperature continues to rise, the weight loss gradually slows and becomes constant. This phenomenon is due to the dehydroxylation process of $\mathrm{Cu}(\mathrm{OH})_{2}$ to form $\mathrm{CuO}$. The thermal decomposition of $\mathrm{Cu}(\mathrm{OH})_{2}$ to produce $\mathrm{CuO}$ and $\mathrm{H}_{2} \mathrm{O}$ takes place at a temperature of approximately $200{ }^{\circ} \mathrm{C}$. Furthermore, the weight loss is observed to be negligible at temperatures above $500{ }^{\circ} \mathrm{C}$. This indicates that an annealing temperature above $500{ }^{\circ} \mathrm{C}$ can be used to convert the precursor solution to $\mathrm{CuO}$. On the basis of the result, a thermal annealing process at $600{ }^{\circ} \mathrm{C}$ for $30 \mathrm{~min}$ or $3 \mathrm{~h}$ was adopted to prepare $\mathrm{CuO}$ films from the present precursor solution.

To investigate the surface morphology of the $\mathrm{CuO}$ films, the precursor sol was spin-coated on a Si substrate and annealed at $600{ }^{\circ} \mathrm{C}$. Figures 2(a) and 2(b) show the FE-SEM images of the surfaces of the $\mathrm{CuO}$ thin films prepared by annealing at $600{ }^{\circ} \mathrm{C}$ for $30 \mathrm{~min}$ and $3 \mathrm{~h}$. It is shown

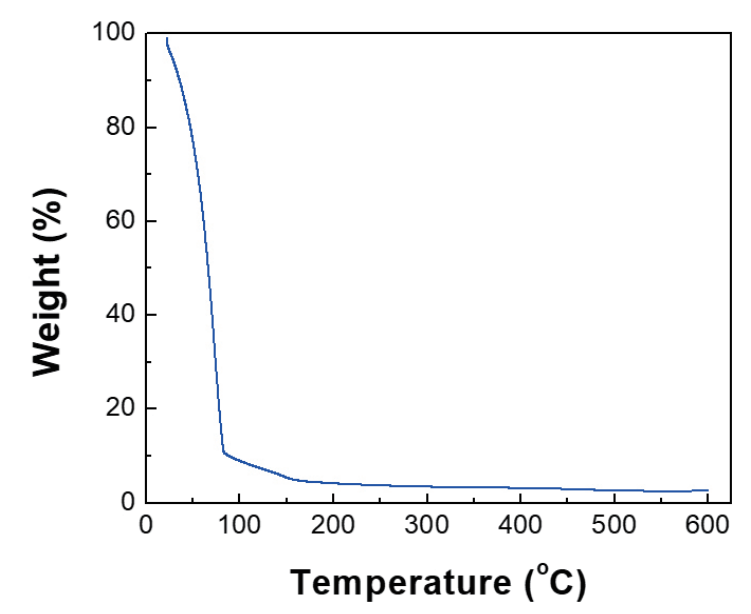

Fig. 1. (Color online) TGA curve of the prepared $\mathrm{CuO}$ precursor solution (plot of weight versus temperature).
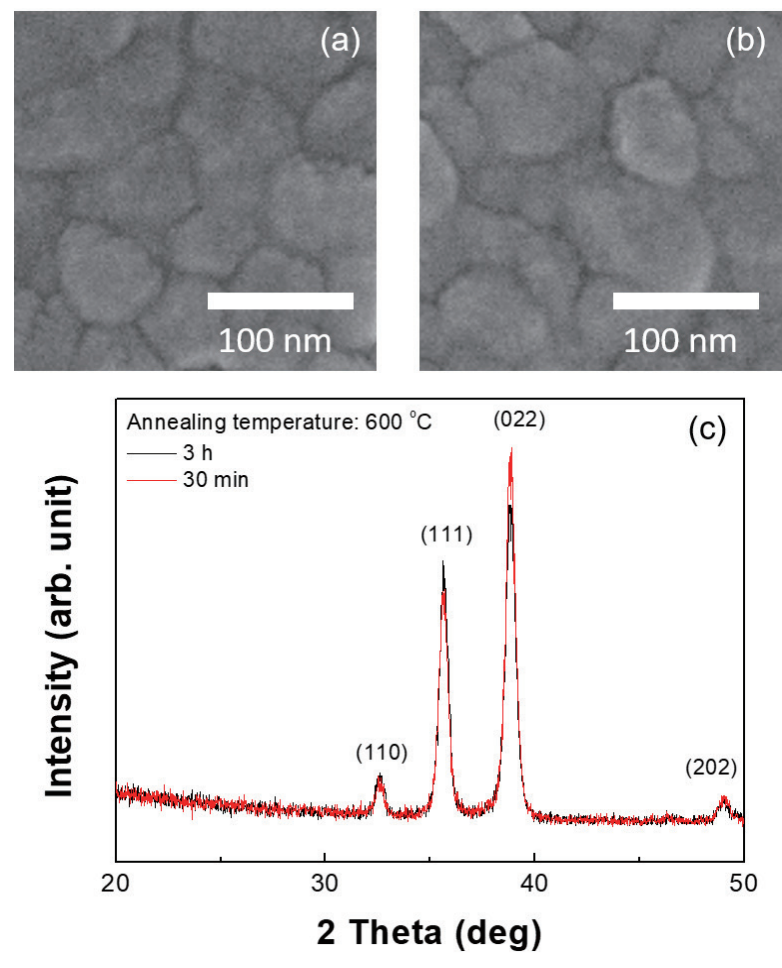

Fig. 2. (Color online) FE-SEM images of $\mathrm{CuO}$ thin films annealed at $600{ }^{\circ} \mathrm{C}$ for (a) $30 \mathrm{~min}$ and (b) $3 \mathrm{~h}$. (c) XRD patterns of the fabricated $\mathrm{CuO}$ films. 
that the grain sizes of the films are similar regardless of the annealing time. This indicates that crystallite coarsening and condensation phenomena are negligibly affected by the annealing time when the films are thermally treated at $600{ }^{\circ} \mathrm{C}$. Figure 2(c) shows the XRD patterns of the solution-processed $\mathrm{CuO}$ films. All the $\mathrm{CuO}$ films exhibit diffraction peaks at approximately $32.7,35.6,38.9$, and $49.0^{\circ}$, which correspond to (110), (002), (111), and (202) planes, respectively. ${ }^{(7)}$ These characteristic peaks can be assigned to the monoclinic symmetry of $\mathrm{CuO}$ (space group $C 2 / c ; a_{0}=4.685 \AA, b_{0}=3.423 \AA, c_{0}=5.132 \AA, \beta=99.47^{\circ}$; JCPDS Card no. 48-1548). ${ }^{(8)}$ In particular, the fact that the peak position and width in the XRD spectra for both films are quite similar suggests that there is no marked difference in the crystallinity of the films annealed for different annealing periods in our experiment. This result indicates that crystal growth in the direction of the characteristic peaks is completed within $30 \mathrm{~min}$.

XPS analysis of the $\mathrm{CuO}$ films was performed to investigate their chemical characteristics. Each XPS spectrum in Fig. 3 shows two distinct peaks at binding energies of approximately 932 and $952 \mathrm{eV}$, corresponding to $2 \mathrm{p}_{3 / 2}$ and $2 \mathrm{p}_{1 / 2}$ states of $\mathrm{Cu}$, respectively. The spin-orbit splitting energy of $20 \mathrm{eV}$, which is derived from the difference between these two binding energies, is in good agreement with the values reported in the literature. ${ }^{(9)}$ The weak band observed at approximately $940-945 \mathrm{eV}$ corresponds to the shake-up satellite structure. The analysis of Fig. 3 indicates that the $\mathrm{Cu} 2 \mathrm{p}$ peaks are shifted to lower binding energies. According to the literature, the result is attributed to a phase change of $\mathrm{Cu}$ from $\mathrm{Cu}(\mathrm{OH})_{2}$ to $\mathrm{CuO}^{(10)}$ Therefore, the performance of the $\mathrm{CuO}$ TFTs can be studied on the basis of the difference in the chemical characteristics of the $\mathrm{CuO}$ films.

The solution-processed $\mathrm{CuO}$ films were also characterized by Raman spectroscopy to analyze the crystal structure of the films. Here, Raman measurements were performed at an excitation wavelength of $532 \mathrm{~nm}$ using a conventional Raman spectrometer. Figure 4 shows the Raman spectra of the solution-processed $\mathrm{CuO}$ films. Apparently, the obtained Raman spectra of $\mathrm{CuO}$ films annealed at $600{ }^{\circ} \mathrm{C}$ for different durations seem similar. The $\mathrm{CuO}$ film annealed for 30 min exhibits Raman peaks at approximately 293, 340, and $626 \mathrm{~cm}^{-1}$, while the corresponding

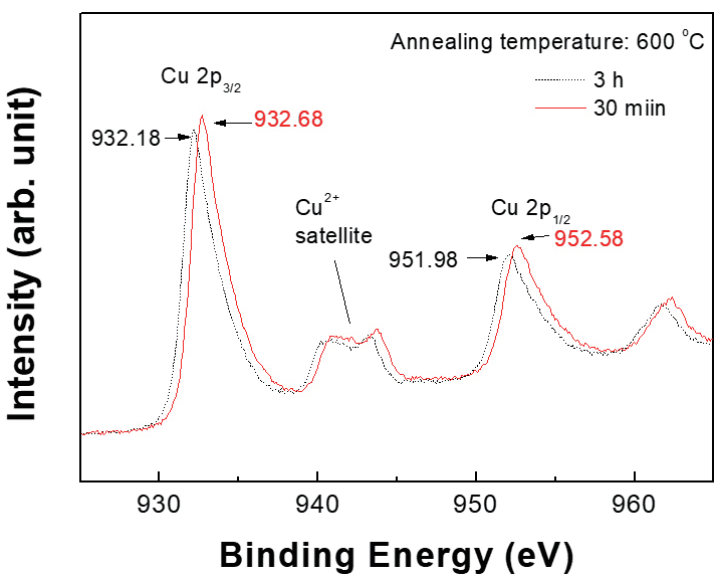

Fig. 3. (Color online) $\mathrm{Cu} 2 \mathrm{p}$ X-ray photoelectron spectra of the fabricated $\mathrm{CuO}$ films.

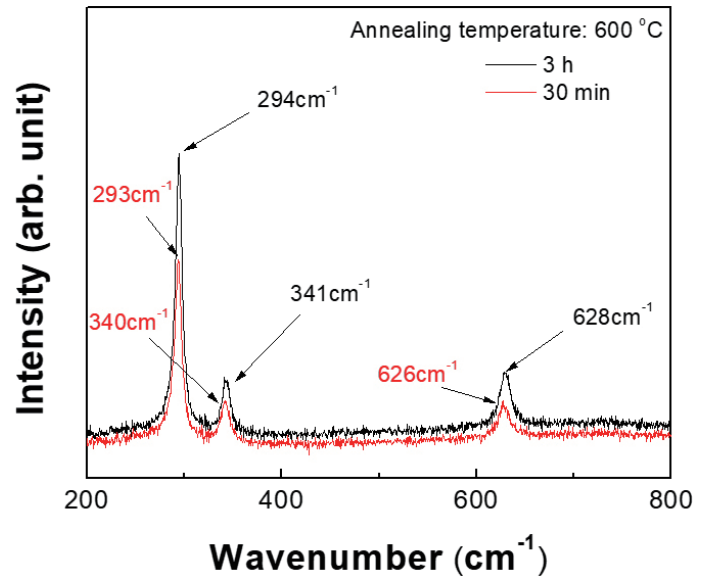

Fig. 4. (Color online) In situ Raman spectra of the fabricated $\mathrm{CuO}$ films. 
Raman peaks in the film annealed for $3 \mathrm{~h}$ are observed at approximately 294, 341, and $628 \mathrm{~cm}^{-1}$. Note that the peak at $293 / 294 \mathrm{~cm}^{-1}$ corresponds to the $\mathrm{Ag}$ mode and the peaks at 340/341 and $626 / 628 \mathrm{~cm}^{-1}$ correspond to the $\mathrm{Bg}$ modes of $\mathrm{CuO}^{(6,11)}$ On the other hand, the shifts in the peak positions towards the high-wavenumber side indicate that the film annealed for $3 \mathrm{~h}$ undergoes compression stress during the annealing process. This potentially explains the agglomeration of nanosized crystallites in the $\mathrm{CuO}$ film upon thermal annealing for a longer period. It is also an important observation that the full width at half maximum properties of these characteristic peaks tend to be reduced and the peak intensities increase with increasing annealing time. The Raman spectroscopy results reveal that the crystallinity of the solution-processed $\mathrm{CuO}$ film can be improved as the annealing time is increased. Therefore, the crystal polymorphism identified by Raman spectra will be significant for understanding the effects of thermal annealing time on the electrical properties of solution-processed $\mathrm{CuO}$ TFTs.

To examine the electrical characteristics of the $\mathrm{CuO}$ thin films prepared with different annealing durations, bottom-gate/top-contact $\mathrm{CuO}$ TFTs were fabricated on $\mathrm{SiO}_{2} / \mathrm{Si}$ substrates. Figures 5(a) and 5(b) show the output characteristics of the fabricated TFTs, measured by changing the drain voltage from 0 to $-20 \mathrm{~V}$ in increments of $-1 \mathrm{~V}$ at different gate voltages. It is seen from the output characteristic curves that the TFTs exhibit p-channel enhancement mode
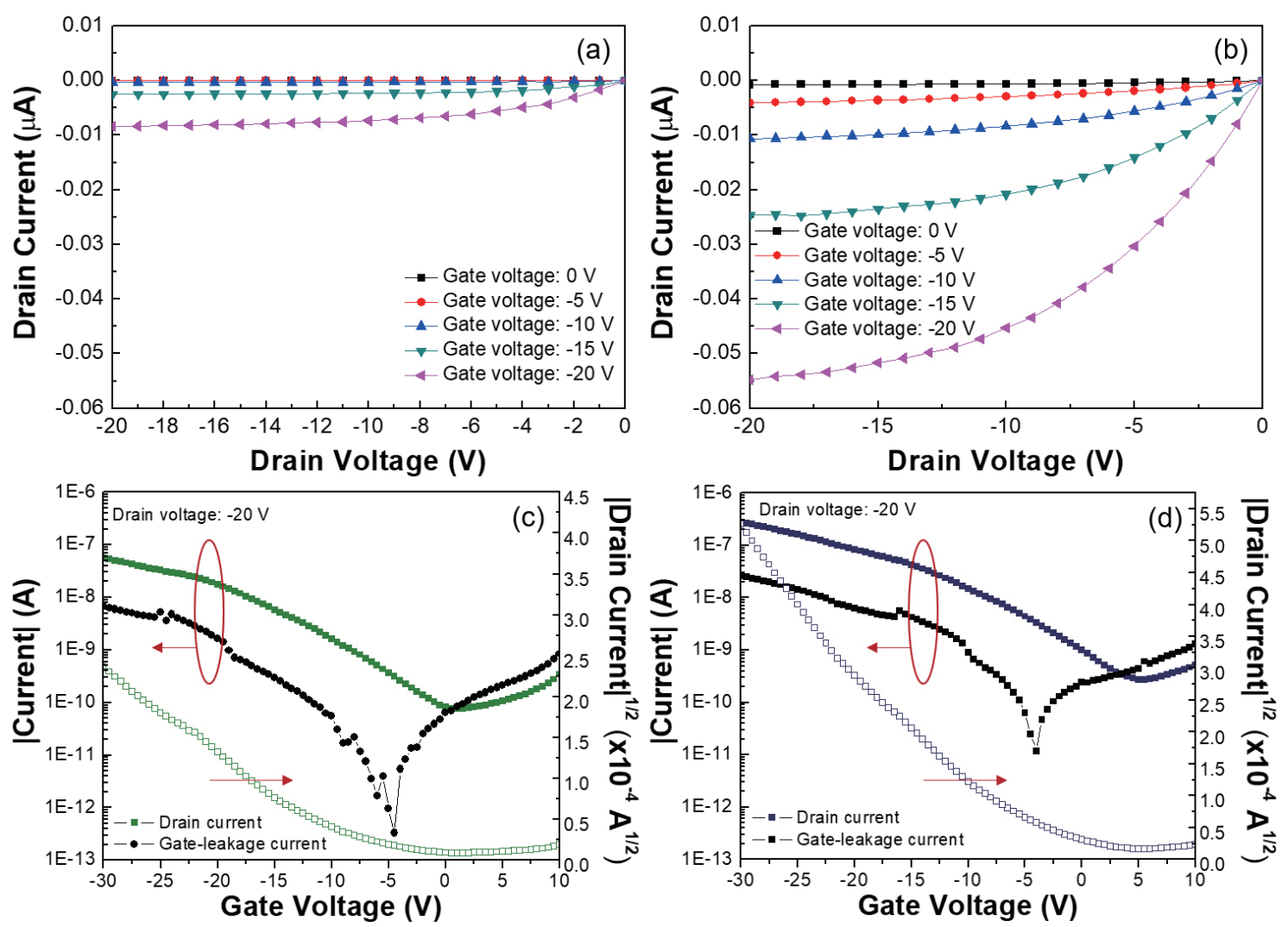

Fig. 5. (Color online) Output and transfer characteristics of TFTs fabricated with $\mathrm{CuO}$ films annealed at $600{ }^{\circ} \mathrm{C}$ for $(\mathrm{a}$, c) $30 \mathrm{~min}$ and $(\mathrm{b}, \mathrm{d}) 3 \mathrm{~h}$. 
operation with pinch-off and saturation characteristics of drain currents. Additionally, the drain current is enhanced as the annealing time of the solution-processed $\mathrm{CuO}$ films increases.

Figures 5(c) and 5(d) show the transfer characteristics of the fabricated $\mathrm{CuO}$ TFTs; the transfer characteristics were measured at a constant drain voltage of $-20 \mathrm{~V}$, while the gate voltage was swept from 10 to $-30 \mathrm{~V}$ in increments of $-1 \mathrm{~V}$. In our results, the CuO TFT annealed for $30 \mathrm{~min}$ exhibited a field-effect mobility of $4.2 \times 10^{-4} \mathrm{~cm}^{2} / \mathrm{Vs}$, threshold voltage of $-8.0 \mathrm{~V}$, and current on/off ratio of approximately $7.3 \times 10^{2}$. Meanwhile, the CuO TFT annealed for $3 \mathrm{~h}$ exhibited a field-effect mobility of $1.5 \times 10^{-3} \mathrm{~cm}^{2} / \mathrm{Vs}$, threshold voltage of $-4.2 \mathrm{~V}$, and current on/off ratio of approximately $1.0 \times 10^{3}$. As the annealing time was increased, the fieldeffect mobility increased and the current on/off ratio increased, while the threshold voltage decreased. This can be ascribed to the enhancement of the electrical properties of $\mathrm{CuO}$ films owing to the enhancement in the crystallinity shown in Raman results and the reduction of $\mathrm{Cu}(\mathrm{OH})_{2}$ shown in Fig. 3. Taking into account the operation frequency of sensor circuits having a TFT amplifier and a TFT switch, the enhancement in the performance of solution-processed CuO-based TFTs in this study is very promising for realizing high-performance sensors with fast signal processing and sensing capabilities. To further improve the TFT performance in terms of current on/off ratio and field-effect mobility, additional research must be carried out. The results of this study show that increasing the amount of $\mathrm{CuO}$ helps to improve the electrical characteristics of solution-processed $\mathrm{CuO}$ TFTs. According to the literature, postdeposition annealing under nitrogen atmosphere, postdeposition annealing under oxygen partial pressure, and vacuum annealing help in the generation of $\mathrm{CuO} .{ }^{(12-14)}$

\section{Conclusions}

We investigated the effects of annealing time on the structural and chemical properties of $\mathrm{CuO}$ films and the electrical properties of $\mathrm{CuO}$ TFTs. Apparently, the FE-SEM and XRD results showed that the crystallinity of the films annealed at $600{ }^{\circ} \mathrm{C}$ is unaffected by the annealing duration as the crystal growth is completed within $30 \mathrm{~min}$. On the other hand, the shift of the $\mathrm{Cu} 2 \mathrm{p}$ peaks in the XPS spectra to lower energies is attributed to the phase transformation of $\mathrm{Cu}$ from $\mathrm{Cu}(\mathrm{OH})_{2}$ to $\mathrm{CuO}$. The analysis of the Raman spectra further revealed that the crystalline properties of the solution-processed $\mathrm{CuO}$ film improved as the annealing time increased. As the annealing time increased, the drain current and field-effect mobility of solution-processed $\mathrm{CuO}$ TFTs increased, but the threshold voltage decreased. The difference in the electrical characteristics of the TFTs with different annealing durations of the solution-processed films is attributed to the formation of $\mathrm{CuO}$. From our results, the optimal annealing duration for a solution-processed $\mathrm{CuO}$ semiconductor was found to be $3 \mathrm{~h}$.

The results of this study are useful for analyzing the structural and electrical properties of solution-processed $\mathrm{CuO}$ semiconductors in TFT applications. We also believe that these results provide a basis for further studies on the development of high-performance sensors fabricated with solution-processed oxide TFT-based circuits. 


\section{Acknowledgments}

This work was supported by the Hallym University Research Fund, 2018 (HRF-201805-009).

\section{References}

1 T. Minami, H. Nanto, and S. Takata: Appl. Phys. Lett. 41 (1982) 958. https://doi.org/10.1063/1.93355

2 T. Minami: Semicond. Sci. Technol. 20 (2005) S35. https://doi.org/10.1088/0268-1242/20/4/004

3 W. Mi, X. Du, C. Luan, H. Xiao, and J. Ma: RSC Adv. 4 (2014) 30579. https://doi.org/10.1039/C4RA02479F

4 S. Knobelspies, B. Bierer, A. Daus, A. Takabayashi, G. A. Salvatore, G. Cantarella, A. O. Perez, J. Wöllenstein, S. Palzer, and G. Tröster: Sensors 18 (2018) 358. https://doi.org/10.3390/s18020358

5 H. Kim, S. Jeon, M. J. Lee, J. Park, S. Kang, H. S. Choi, C. Park, H. S. Hwang, C. Kim, J. Shin, and U. I. Chung: IEEE Trans. Electron Devices 58 (2011) 3820. https://doi.org/10.1109/TED.2011.2165286

6 Y. Deng, A. D. Handoko, Y. Du, S. Xi, and B. S. Yeo: ACS Catal. 6 (2016) 2473. https://doi.org/10.1021/ acscatal.6b00205

7 A. Liu, S. Nie, G. Liu, H. Zhu, C. Zhu, B. Shin, E. Fortunato, R. Martins, and F. Shan: J. Mater. Chem. C 5 (2017) 2524. https://doi.org/10.1039/C7TC00574A

8 B. Zhao, P. Liu, H. Zhuang, Z. Jiao, T. Fang, W. Xu, B. Lu, and Y. Jiang: J. Mater. Chem. A 1 (2013) 367. https://doi.org/10.1039/C2TA00084A

9 Z. H. Gan, G. Q. Yu, B. K. Tay, C. M. Tan, Z. W. Zhao, and Y. Q. Fu: J. Phys. D: Appl. Phys. 37 (2004) 81. https://doi.org/10.1088/0022-3727/37/1/013

10 M. C. Biesinger, L. W. M. Laua, A. R. Gersonb, and R. St. C. Smart: Appl. Surf. Sci. 257 (2010) 887. https:// doi.org/10.1016/j.apsusc.2010.07.086

11 M. Rashad, M. Rüsing, G. Berth, K. Lischka, and A. Pawlis: J. Nanomater. 2013 (2013) 714853. http://doi. org/10.1155/2013/714853

12 S. Y. Kim, C, H. Ahn, J. H. Lee, Y. H. Kwon, S. Hwang, J. Y. Lee, and H. K. Cho: ACS Appl. Mater. Interfaces 5 (2013) 2417. https://doi.org/10.1021/am302251s

13 J. Yu, G. Liu, A. Lio, Y. Meng, B. Shin, and F. Shan: Mater. Chem. C 3 (2015) 9509. https://doi.org/10.1039/ C5TC02384J

14 Z. Wang, P. K. Nayak, J. A. Caraveo-Frescas, and H. N. Alshareef: Adv. Mater. 28 (2016) 3831. https://doi. org/10.1002/adma.201503080 